Niniejsza publikacja jest dostęna na licencji Creative Commons. Uznanie autorstwa-Użycie niekomercyjne-Bez utworów zależnych 3.0 Polska. Pewne prawa zastrzeżone na rzecz autora. Zezwala się na wykorzystanie publikacji zgodnie z licencja - pod warunkiem zachowania niniejszej informacji licencyjnej oraz wskazania autora jako właściciela praw do tekstu. Treść licencji jest dostępna na stronie: http://creativecommons.org/licenses/by-nc-nd/3.0/pl/

Lingwistyka Stosowana 19: 4/2016, 167-183

\author{
Mariusz MARCZAK
}

Uniwersytet Jagielloński

\title{
Podejście międzykulturowe a rozwijanie kompetencji translatorskiej
}

\begin{abstract}
:
Intercultural Methods and the Development of Translator Competence

This paper deals with the development of translator competence, comprising a group of both cognitive and practical sub-competences, at university level. According to the model of translodidactics, proposed by F. Grucza (2004), the central determiner of attainment in translation pedagogy is a set of skills to be developed in a student translator. This set embraces linguistic-cultural skills, translation skills as well as other skills which may significantly affect the degree to which students master translation. The author of this paper will focus, in particular, on the possibility of developing 4 major groups of translator competences - based on competence models proposed by PACTE group (2003) or EMT expert group (2009) and pertaining to: language, culture, text and translation problem-solving - with the implementation of ethnographic, empirical, dialogic and comparative teaching methods, derived from M. Byram's $(1997,2008)$ Intercultural Approach to foreign language teaching.
\end{abstract}

\section{Wstęp}

Skuteczność pedagogiki przekładu zależy w znacznej mierze od tego, na ile dokładnie precyzuje ona kompetencje tłumacza, który byłby w stanie efektywnie wywiązywać się z zadań powierzanych mu w toku przyszłej pracy zawodowej. Zestaw takowych kompetencji określa się ogólnie mianem kompetencji translatorskiej, która swoim zakresem obejmuje kognitywną kompetencję translatoryczną oraz praktyczną kompetencję translacyjną. Kompetencja translatorska nie jest zatem tożsama z kompetencją bilingwalną, a wykracza poza nią. F. Grucza $(1981,1985)$ określa ją mianem swoistej kompetencji bilingwalnej, która zasięgiem wykracza poza umiejętność operowania dwoma językami adekwatnymi do zadań tłumaczeniowych. Jak dodaje J. Żmudzki (2009), kompetencja ta stanowi istotną wartość dodaną w stosunku do bilingwalnej kompetencji lingwistyczno-komunikacyjnej, a wraz z doświadczeniem u każdego tłumacza podlega dalszemu rozwojowi. Na skutek tego, poszczególni thumacze rozwijają $\mathrm{w}$ toku praktyki zawodowej własną teorię translacji, składającą się z "(...) wytworzonych przez siebie specyficznych reguł i umiejętności translacyjnych stanowiących określoną wartość dodaną lub też nadwyżkę jego umiejętności oraz określoną wartość dodaną lub też nadwyżkę wiedzy" (J. Żmudzki 2009: 52). 
Wykorzystanie modeli kompetencji translatorskiej pomaga odpowiednio zaplanować proces kształcenia thumacza tak, by obejmował on swoim zasięgiem wszystkie niezbędne elementy. Jednocześnie, modele te pozwalają w czytelny sposób dla nauczycieli, jak i translatorów-uczniów zoperacjonalizować cele stawiane dydaktyce translacji czy też translodydaktyce (zob. M. Płużyczka 2009). Całość procesu, w ramach którego cele te można zrealizować, przedstawia zaproponowany przez S. Gruczę (2004), model układu translodydaktycznego, zilustrowany graficznie poniżej:

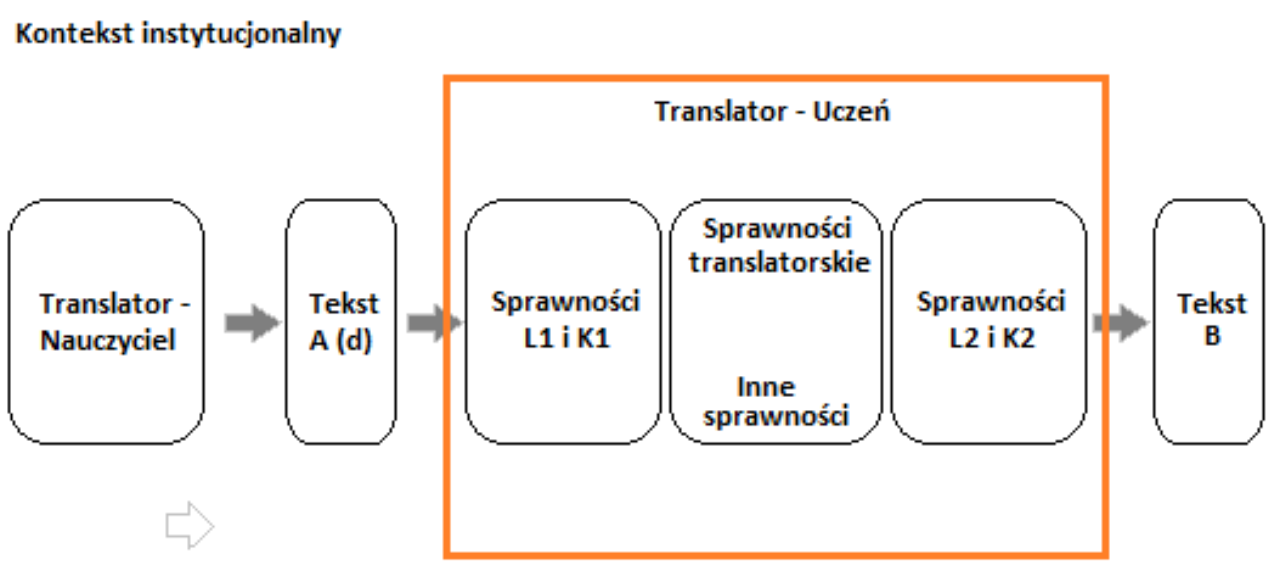

Schemat 1. Układ translodydaktyczny wg S. Gruczy (2004).

Według założeń S. Gruczy (2004), proces kształcenia tłumacza odbywa się w kontekście instytucjonalnym, stanowiącym środowisko, w którym funkcjonuje translator-nauczyciel oraz translator-uczeń. Na poziomie instytucjonalnym czynnikiem wpływającym na skuteczność kształcenia jest przede wszystkim translatornauczyciel, który czuwa nad odpowiednim zaplanowaniem, przebiegiem i ocenianiem realizowanego procesu dydaktycznego. Jego decyzje wpływają przecież na konstrukcję programu nauczania translacji, dobór właściwych treści, metod i technik nauczania, a także materiałów i pomocy dydaktycznych.

W takim właśnie środowisku funkcjonuje translator-uczeń, którego zadaniem jest rozwinięcie całej gamy sprawności niezbędnych do skutecznego pośredniczenia w komunikacji pomiędzy nadawcą tekstu źródłowego a odbiorcą tekstu docelowego. Choć efekt końcowy procesu dydaktycznego jest wypadkową wszelkich interakcji, jakie zachodzą pomiędzy jego elementami, na uwagę zasługuje fakt, że w omawianym schemacie układu translodydaktycznego w centrum znajduje się uczeń, a zatem zarówno posiadane już przez niego sprawności, jak i te, które nadal rozwija - lub będzie rozwijał w przyszłości - należy traktować jako determinanty w najwyższym stopniu wpływające na efekty kształcenia. Sprawności te obejmują przede wszystkim elementy językowo-kulturowe powiązane z kompetencją ucznia w zakresie pary języków adekwatnej do zadań thumaczeniowych, do których jest przygotowywany, nie są jednak wyłącznie do nich ograniczone. Równie ważne są bowiem także sprawności stricte translatorskie oraz wszelkie inne sprawności, które mogą deter- 
minować ostateczny poziom osiągnięć translatora-ucznia, a ich zakres odnaleźć można w licznych, zaproponowanych dotychczas modelach kompetencji translatorskiej.

\section{Modele kompetencji translatorskiej}

Jak wspomniano wyżej, kompetencję translatorską określić można jako zbiór kompetencji kognitywnych i praktycznych. Jednakże, proponowane w literaturze fachowej modele kompetencyjne wskazują również na potrzebę rozwijania u translatoraucznia innych rodzajów kompetencji, np. metakognitywnych czy afektywnych, związanych z postawami, a także opartych na umiejętności poddawania podejmowanych przez translatora-ucznia działań krytycznej refleksji, tak by nie tylko doskonalić rozwinięte dotychczas sprawności czy zdobywać nowe, ale również nabywać umiejętność skutecznego odkrywania wiedzy i uczenia się.

Przykładem takiego ujęcia kompetencji translatorskiej jest holistyczny model kompetencji zaproponowany przez grupę PACTE (2003), który obejmuje zarówno wiedzę deklaratywną, proceduralną, jak i elementy poznawcze oraz afektywne.

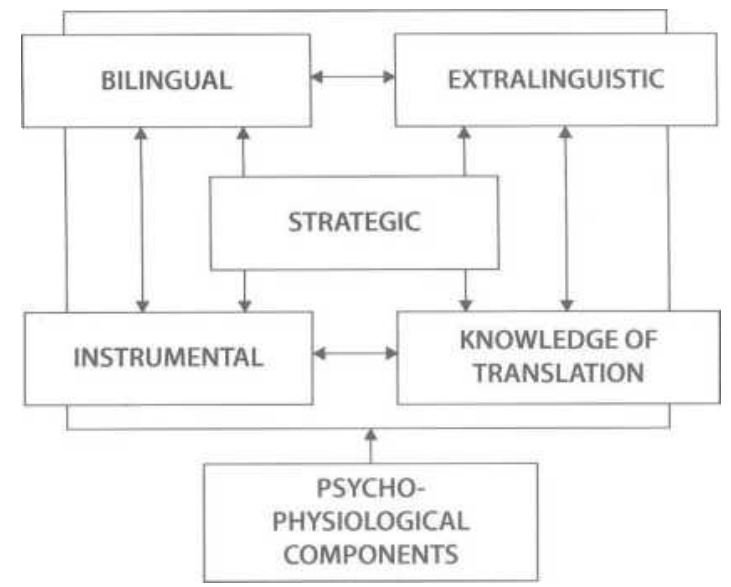

Schemat 2. Model kompetencji translatorskiej wg PACTE group (2004: 319).

Składowe kompetencje bilingwalne w tym modelu odnoszą się do umiejętności komunikowania się $\mathrm{w}$ dwóch językach i obejmują wiedzę proceduralną na poziomie pragmatycznym, społeczno-językowym, tekstowym, gramatycznym i leksykalnym. Obejmują więc, między innymi, kompetencję tekstową, którą Montalt Ressurrecció, Piorno i Izquierdo (2008) określają, jako biegłość w tworzeniu rozmaitych gatunków lub rodzajów tekstów pisemnych/ ustnych z wykorzystaniem odpowiednich form językowych.

Kompetencje pozajęzykowe to przede wszystkim wiedza deklaratywna: ogólna wiedza o świecie, wiedza fachowa dotycząca konkretnej dziedziny, wiedza międzykulturowa oraz encyklopedyczna. Wiedza ta musi być jednak uzupełniona również o wiedzę dotyczącą procesu przekładu, głównie w zakresie funkcjonowania przekładu, znajomości aspektów zawodu tłumacza oraz elementów praktyki zawodowej, jak 
również kompetencje instrumentalne, które stanowią umiejętności wykorzystywania zasobów dokumentacyjnych oraz technologii informacyjno- komunikacyjnych mających zastosowanie w przekładzie, np. słowników, encyklopedii, elektronicznych korpusów językowych lub wyszukiwarek.

Kompetencje strategiczne odnoszą się do konkretnych umiejętności praktycznych, pozwalających rozwiązywać napotkane problemy tak, by zapewnić efektywność thumaczenia na poszczególnych etapach: planowania, przebiegu, oceny i wdrażania procedur naprawczych.

Wreszcie, model PACTE obejmuje elementy natury psychofizjologicznej: obejmujące procesy poznawcze, np. postawy i mechanizmy psychomotoryczne, w tym (i) komponenty poznawcze, takie jak pamięć czy percepcja, (ii) postawy: ciekawość, wytrwałość, zdyscyplinowanie, umiejętność krytycznego myślenia oraz (iii) umiejętności, takie jak: kreatywność, analiza i synteza.

W ramach wysiłków podejmowanych na rzecz jak najdokładniejszego sprecyzowania części składowych kompetencji translatorskiej zaproponowano wiele innych jej modeli (zob. G. Winkler 1992/ R. Sim 2000/ A. Pym 2003/ P. Kastberg 2007). Niektóre $z$ nich to modele minimalistyczne, określające $w$ stopniu bardzo ogólnym tylko najistotniejsze, z punktu widzenia autorów, komponenty składowe kompetencji translatorskiej (zob. A. Pym 2003). Inne zaś rozbudowano bardziej, kładąc przy tym nacisk na wybrane grupy kompetencji, np. poznawczych i językowych - często w odniesieniu do konkretnego typu przekładu, np. przekładu specjalistycznego (zob. G. Winkler 1992/ P. Kastberg 2007 ) - bądź też na praktyczne kompetencje translacyjne. Zaproponowane modele podzielić można również na pedagogiczne i empiryczne, w zależności od założeń, jakie postawili sobie ich autorzy. O ile modele pedagogiczne stanowią próbę odpowiedzi na problemy towarzyszące procesowi kształcenia thumaczy (zob. Schaeffner 2000), o tyle modele empiryczne odzwierciedlają wyniki badań empirycznych dotyczących przebiegu procesu thumaczeniowego (zob. S. J. Campbell 1991) bądź badań, które w sposób empiryczny próbowały zweryfikować założenia modeli teoretycznych (zob. PACTE group 2003).

Nie zaproponowano zatem jednego, powszechnie uznanego modelu kompetencji translatorskiej, lecz kilka równocześnie funkcjonujących modeli, które w wybranych aspektach się pokrywają, w innych zaś wzajemnie uzupełniają.

Modelem kompetencji translatorskiej, który może pomóc w uporządkowaniu dotychczas zaproponowanych rozwiązań jest model zaproponowany w ramach programu European Master's in Translation (EMT expert group 2009), stanowiący krok ku unifikacji systemów kształcenia tłumaczy oraz wymogów kompetencyjnych stawianych thumaczom w krajach członkowskich Unii Europejskiej. 


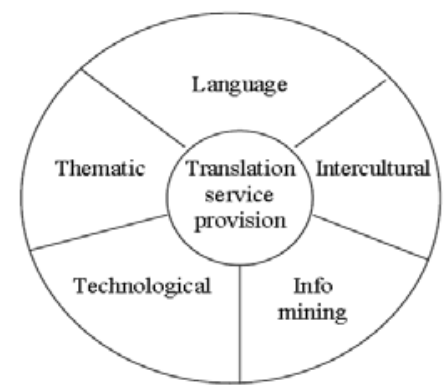

Schemat 3. Model kompetencji ttumacza wg EMT expert group (2009: 4).

Jak wskazuje graficzna ilustracja modelu EMT, jego centralny element stanowi ogólnie pojęta umiejętność świadczenia usług w zakresie tłumaczeń pisemnych, która obejmuje dwa wymiary: interpersonalny i produktywny. Wymiar interpersonalny dotyczy wiedzy i umiejętności pozwalających nawiązywać właściwe relacje z klientami, odbiorcami tekstu i innymi stronami zaangażowanymi w proces tłumaczenia, wykonywać thumaczenia grupowe, z uwzględnieniem wszelakich standardów formalno-etycznych, a także dokonywać samooceny. Natomiast wymiar produktywny odnosi się bezpośrednio do samego tłumaczenia, podczas którego należy wykazać się między innymi umiejętnością: odpowiedniej organizacji pracy, doboru uzasadnionych strategii thumaczeniowych, diagnozowania i rozwiązywania napotkanych problemów.

Umiejętność świadczenia usług w zakresie tłumaczeń z jednej strony obejmuje zasięgiem wszystkie kompetencje zawarte w modelu EMT, a jednocześnie stanowi wypadkową stopnia, w jakim tłumacz jest w stanie praktycznie je wykorzystać, a są to: kompetencje językowe i międzykulturowe, kompetencje w zakresie wyszukiwania informacji, kompetencje techniczne oraz kompetencje dziedzinowe.

Kompetencje językowe i międzykulturowe obejmują biegłą znajomość języka źródłowego i docelowego, umiejętność streszczania tekstów oraz zdolność rozumienia informacji i elementów kulturowych zawartych w tekście. Kompetencje w zakresie wyszukiwania informacji dotyczą zdolności, które z jednej strony pozwalają skutecznie dotrzeć do niezbędnych informacji, a z drugiej, krytycznie zweryfikować źródła danych. Kompetencje techniczne umożliwiają korzystanie $\mathrm{z}$ technologii thumaczeniowych, np. pamięci thumaczeniowych, jak również efektywne zarządzanie terminologią. W końcu, kompetencje dziedzinowe obejmują wiedzę w zakresie dziedzin specjalistycznych, adekwatnych do wykonywanego zadania thumaczeniowego, jak również umiejętność jej praktycznego zastosowania.

Kompetencje składowe zaproponowanych dotychczas modeli kompetencji translatorskiej wykazują wspólny mianownik, którym jest uwzględnienie kompetencji thumacza w odniesieniu się do czterech głównych elementów:

- języka (kompetencja językowa);

- kultury (kompetencja [inter]kulturowa);

- tekstu (kompetencja tekstowa, kompetencja dziedzinowa); 
- rozwiązywania problemów przekładowych (kompetencja w zakresie wyszukiwania informacji, kompetencja techniczna, kompetencja transferu, umiejętność uczenia się przez całe życie).

Niniejszy artykuł stawia sobie za cel rozważenie, w jakim stopniu podejście międzykulturowe do nauczania języków obcych może okazać się pomocne w rozwijaniu kompetencji translatora-ucznia. W związku z tym, poniżej pokrótce omówione zostaną główne metody pracy wykorzystywane $\mathrm{w}$ obrębie podejścia międzykulturowego, a następnie omówiony zostanie stopień, w którym metody te mogą okazać się pomocne w rozwijaniu głównych elementów kompetencji translatorskiej, omówionych powyżej.

\section{Podejście międzykulturowe w dydaktyce języka}

Istnieją cztery główne metody międzykulturowego nauczania języków obcych: (i) metody etnograficzne, (ii) metody empiryczne, (iii) metody dialogiczne oraz (iv) metody porównawcze. Przy czym, należy mieć świadomość, że żadna z tych metod nie zajmuje w założeniu dominującej pozycji w stosunku do innych. Są one raczej traktowane jako wzajemne uzupełnienie i pomagają wzbogacić repertuar środków, za pomocą których rozwijać można wiedzę międzykulturową, umiejętności praktyczne i pożądane postawy uczniów.

\subsection{Metody etnograficzne}

Nauczanie kultury poprzez etnografię, za którym opowiadają się, między innymi A. Barro i in. (1998), L. Sercu (1998) oraz J. Corbett (2003), polega na zapisywaniu, porównywaniu, thumaczeniu i objaśnianiu konkretnych doświadczeń kulturowych lub międzykulturowych. Metody etnograficzne umożliwiają uczniom odkrywanie zjawisk kulturowych za pośrednictwem obserwacji uczestniczącej (A. Cooper 1998), w ramach której zbierają oni informacje kulturalne i analizują je doświadczając - w mniej lub bardziej bezpośredni sposób - odmiennych, nieznanych im bliżej kultur.

Metody etnograficzne pozwalają na naukę poprzez doświadczenie, która umożliwia uczniom budowanie w niezależny i nienarzucony sposób własnego wizerunku poznawanych kultur $\mathrm{w}$ oparciu o wnioski płynące $\mathrm{z}$ osobistych doświadczeń. W optymalnej formie doświadczenia takie powinno się zbierać w kraju docelowym, gdzie uczniowie są w stanie wejść $\mathrm{w}$ bezpośrednie interakcje $\mathrm{z}$ przedstawicielami innych kultur na gruncie życia codziennego. Jednakże, nawet jeśli okazuje się to niemożliwe, bezpośrednie doświadczenie zastąpić można działaniami umożliwiającymi zbieranie takich doświadczeń, wykorzystując do tego celu techniki interpretacyjne. Przykładem nauki w takim trybie są zadania wymagające interpretacji tekstu, poprzez którą możliwe jest odkrywanie odmienności kulturowych w sposobie, $\mathrm{w}$ jaki wybrane społeczności postrzegają rzeczywistość. Warto w tym miejscu podkreślić, że interpretacja tekstu wykracza w tym wypadku poza granice analizy hermeneutycznej. Jak proponuje J. Corbett (2003), tekst kulturowy należy postrzegać szerzej niż klasyczne dzieła literackie, gdyż obejmować może on również bajki, a na- 
wet formy graficzno-werbalne lub graficzne, np. komiksy, plakaty, obrazy i fotografie.

Kolejna technika etnograficzna opiera się na budowaniu empatii uczniów (L. Sercu 1998, J. Corbett 2003), co ma pozwolić im wniknąć w umysł przedstawicieli innych kultur tak, by poczuć, jakie emocje mogą odczuwać, uczestnicząc w konkretnych wydarzeniach kulturalnych. Wrażliwość tego typu jest nieodzowna, by skutecznie przygotować uczniów do podejmowania mediacji w międzykulturowych sytuacjach komunikacyjnych.

Ciekawym pomysłem jest wykorzystanie techniki etnograficznej zaproponowanej przez M.C. Cevasco (1998), który sugeruje, by uczniowie dodatkowo analizowali produkty kulturowe, korzystali z dokonań semiotyki podczas kulturowej analizy tekstów lub próbowali określić profil odbiorców wybranego tekstu na podstawie zawartych w nim treści.

Jak twierdzi J. Corbett (2003), techniki etnograficzne pomagają uczącym się osiągnąć jeden z podstawowych celów nauczania międzykulturowego, którym według M. Byrama (1997) jest rozwijanie zdolności postrzegania innej kultury (K2) z perspektywy autochtonów, jak również umiejętności spojrzenia na własną kulturę (K1) z perspektywy obcych. Choć realizacja obu wymiarów tego celu stanowi wyzwanie, jest jednak możliwa, a uczeń, który tego dokona będzie w stanie znaleźć się w tzw. trzecim miejscu (C. Kramsch 1996), tzn. abstrakcyjnym punkcie, równoodległym od obu wspomnianych kultur (K1 i K2), które pozwala w sposób obiektywny z powodzeniem pośredniczyć między nimi pomimo różnic, które je charakteryzują.

Działaniem wspomagającym osiągnięcie wyżej wspomnianego celu jest również wykorzystanie etnografii domowej (home ethnography z ang.) (A. Barro i in. 1993), która polega na obserwacji kultury rodzimej, co pomaga uczniowi rozwijać umiejętności etnograficzne, a także jednocześnie zdystansować się od własnej kultury (A. Barro i in. 1998). Docelowo uczeń ma również nauczyć się radzić sobie w sytuacjach na styku kultur oraz rozwinąć zdolność rozróżniania kulturowo determinowanych wzorców komunikacyjnych (J. Corbett 2003).

\subsection{Metody empiryczne}

Metody empiryczne wykorzystywane są w podejściu międzykulturowym w dwojakim celu. Z jednej strony mają wspomagać rozwijanie świadomości kulturowej i postaw niezbędnych do skutecznej mediacji międzykulturowej; $\mathrm{z}$ drugiej strony mają na celu pomóc uczniom w opanowaniu umiejętności komunikacji międzykulturowej w czasie rzeczywistym.

Jest oczywiste, że umiejętności te można najskuteczniej rozwinąć w naturalnym środowisku komunikacyjnym (A. Fenner 2000), gdzie uczniowie mogą aktywnie konstruować wiedzę poprzez doświadczenie, a nie poprzez odbiór przekazywanej przez nauczyciela wiedzy deklaratywnej. Warto podkreślić, że również w tym przypadku uczeń buduje własny obraz poznawanej/ doświadczanej kultury, jedynie przy wsparciu ze strony nauczyciela.

Jak twierdzi C. Kramsch (1993), tego typu nauka, zgodna z założeniami konstruktywizmu poznawczego, sprawia, że uczniowie poznający dane systemy języka, 
stale budują i rekonstruują znaczenia, lecz działania takie wykraczają daleko poza sam język i obejmować mogą również inne elementy kultury, takie jak: zachowania i artefakty, a to z kolei pozwala na eksplorację wzorców myślowych, przekonań i perspektyw, które stanowią ukryte - a więc trudniejsze do zauważenia i zbadania warstwy kultury.

Metody empiryczne kładą nacisk na doświadczanie różnic kulturowych, obiektywną refleksję nad nimi oraz wnioskowanie, dzięki czemu uczniowie nie tylko zdobywają nową wiedzę i umiejętności, ale również mają okazję wykorzystać je praktycznie $\mathrm{w}$ interakcji międzykulturowej. Naturalnie, aby taki sposób uczenia się przyniósł spodziewane efekty, potrzeba czasu i systematyczności, co doskonale oddaje cykl uczenia się w oparciu o nowe doświadczenia, zaproponowany przez D. Kolba (1984), który obejmuje cztery etapy: doświadczenie, obserwacja i refleksja, wnioskowanie i wypracowanie teorii/ wiedzy oraz zastosowanie wypracowanej wiedzy w praktyce.

Doświadczenia międzykulturowe, które optymalnie odpowiadają konstruktywistycznemu modelowi uczenia się najlepiej zdobywać poprzez bezpośredni kontakt z odmiennością (L. Sercu 1998), np. podczas pobytu za granicą. Jednak mogą one również być symulowane w klasie przy wsparciu ze strony innych uczniów i nauczyciela na wypadek, gdyby doświadczane zjawiska kulturowe okazały się zbyt przytłaczające (V. Kohonen i in. 2001).

L. Raw (1998) podaje konkretne techniki, które mogą być wykorzystane do nauki poprzez doświadczenie, dzięki czemu uczniowie mogą porównywać kultury, badać i dekonstruować uprzedzenia oraz stereotypy. Zadania takie różnią stopniem skomplikowania i obejmować mogą zarówno krótkie ćwiczenia, które stanowić mogą rozgrzewkę podczas zajęć, jak i bardziej wymagające zadania oparte na tekstach czytanych lub zadania projektowe, wykonywane w grupie. Jak proponują V. Kohonen i inni (2001), w celu zapisywania doświadczeń i ich analizy uczniowie mogą wykorzystać, między innymi: prowadzenie dziennika lub portfolio, czynny lub bierny udział w występach teatralnych, przedstawiających symulowane scenki międzykulturowe, zadania wymagające rozwiązywania problemów oraz studia przypad$\mathrm{ku}$. Zadania te uzupełnić można również o: pisanie pamiętników lub badania terenowe w oparciu o ankiety lub wywiady (zob. A. Barro i in. 1993).

\subsection{Metody dialogiczne}

Metody dialogiczne umożliwiają uczniom poznawanie mechanizmów rzadzących konstrukcją i dekonstrukcją tekstu. Zgodnie z założeniami, które przyświecają ich stosowaniu, metody te mają uświadomić uczniom, że treści zapisane w tekście zostają najpierw zakodowane przez autora, zgodnie z jego własną perspektywą kulturową i schematami percepcyjnymi, a następnie - by tekst spełnił funkcję komunikacyjną - muszą zostać z powodzeniem odkodowane przez odbiorcę tak, by ten ostatni zrozumiał je w sposób zbieżny z intencjami autora.

Oczekiwanym wynikiem takiego uczenia się jest uświadomienie uczniom, że jeśli autor tekstu i jego odbiorca reprezentują różne grupy kulturowe - narodowe na 
poziomie społeczności, a nawet idiosynkratyczne - odkodowany komunikat może znacząco różnić się od treści, które w zamyśle zamierzał przekazać autor tekstu.

Według Caspariego (zob. A. Müller-Hartmann 2000), metody dialogiczne powinny opierać się na: technikach wprowadzających do czytania właściwego (prereading $\mathrm{z}$ ang.), technikach czytania ze zrozumieniem oraz technikach podsumowujących przeczytany tekst (post-reading z ang.). Dzięki ich zastosowaniu, uczniowie mają w pierwszym rzędzie podejść do czytanego tekstu z ciekawością i jednoczesną świadomością jego tła kulturowego, co wspomagać ma właściwą interpretację treści podczas czytania. Następnie, próbują odkodować przekaz tekstu z zamiarem interpretacji i oceny kultury, którą czytany tekst reprezentuje. Wreszcie, mają za zadanie zinterpretować znaczenia zawarte $\mathrm{w}$ tekście, uwzględniając przy tym perspektywę poznawczą autora i własną.

W pierwotnym założeniu, podejście dialogiczne stawia na analizę hermeneutyczną jako narzędzie umożliwiające rozwijanie wiedzy, umiejętności i świadomości niezbędnych w komunikacji międzykulturowej. Jednak przy okazji, pomaga również podkreślić wyzwania, którym podołać musi tłumacz kiedy mediując między tekstem źródłowym i docelowym, usiłuje odkodować treści źródłowe, a następnie zakodować je ponownie - tym razem w języku docelowym - zgodnie ze schematami poznawczymi potencjalnego odbiorcy przetłumaczonego tekstu.

\subsection{Metody porównawcze}

Podejście porównawcze (zob. M. Byram 1997/ B. Edgington 2000), jak sama nazwa wskazuje, polega na analizie porównawczej kultury rodzimej i innej kultury. Należy jednak pamiętać, by porównanie nie sprowadzało się do opracowania listy zaobserwowanych podobieństw i różnic kulturowych, ponieważ taka praktyka prowadzić będzie jedynie do płytkich refleksji, które wzmocnią pozytywne i negatywne stereotypy uczniów na temat obu kultur. Porównanie może obejmować analizę informacji, interpretację zdarzeń oraz ocenę trafności zebranych danych (H. Kastendiek 2000).

Jak proponuje M. Byram (1989), porównanie prowadzić ma do relatywizacji i ukontekstowienia kultury rodzimej na skutek poszerzania wiedzy o innych kulturach. Stąd też ważne jest, by uczniowie potrafili odnieść obserwacje dotyczące obcej kultury do kultury rodzimej, co pomoże im nie tylko zobiektywizować tą ostatnią, lecz również uświadomić sobie, że sposób postrzegania siebie i odmienności kulturowych w dużej mierze zależny jest od kultury rodzimej (B. Edgington 2000). M. Byram i in. (1994) podkreślają, że kulturowa analiza kontrastywna musi umożliwiać uczącym się rozwijanie świadomości istnienia odmiennych zbiorów wartości i przekonań, które leżą u podstaw poszczególnych systemów kulturowych.

Ogromne znaczenie ma wykorzystanie podczas pracy z uczniem analizy porównawczej, która może dotyczyć zarówno podobieństw, jak i różnic. Niezależnie od wyboru, nacisk na oba te bieguny musi być zrównoważony tak, by uczniowie mogli przemyśleć obserwowane zjawiska, unikając negatywnych stereotypów lub pochopnych wniosków na temat tożsamości badanych kultur (B. Edgington 2000).

Ponadto należy unikać błędnego założenia, że jedna z porównywanych kultur stanowi punkt wyjściowy do obserwacji zjawisk. Innymi słowy, ważne jest, aby nie 
analizować innej kultury z perspektywy etnocentrycznej, nie rozwijać przekonania, że kultura rodzima dominuje nad docelową (B. Edgington 2000), gdyż wyniki analizy międzykulturowej zależą właśnie od sposobu, w jaki jest ona realizowana oraz od natury refleksji i dyskusji, które po analizie porównawczej następują. M. Byram i in. (1994) twierdzą, że kulturowa analiza porównawcza powinna wykraczać poza kulturę narodową tak, by uczniowie rozumieli złożoność i wielowymiarowość tego, co powszechnie postrzegane jest jako kultura narodowa.

Podsumowując, można stwierdzić, że podejście porównawcze jest zbieżne z ideą strategii oddolnego uczenia się (bottom-up strategy z ang.) (R. Bolt 2001), która wykorzystywana jest w nauczaniu międzykulturowym i polega na tym, że nauczyciel nie przekazuje uczniom z góry określonych poglądów czy obrazów świata. Poglądy takie muszą ukształtować niezależnie sami uczniowie, co pomoże im na własną rękę odczytywać zagadnienia kulturowe, unikając przy tym stereotypów (J. Collie 2000/ D. Kołodziejczyk i in. 1998).

Przykładowe zadania międzykulturowe obejmują, między innymi, następujące formy: indukowanie informacji na podstawie analizy produktów kultury, np. reklam, refleksję nad kulturą rodzimą, odkrywanie innych kultur poprzez analizę wzorców zachowań i wyrażeń językowych, a także wywiady z obcokrajowcami (zob. B. Tomalin i S. Stempleski 1993/ M. Huber-Kriegler i in. 2003).

\section{Metody nauczania międzykulturowego $\mathrm{w}$ dydaktyce przekładu}

Celem niniejszego artykułu jest przeanalizowanie, w jak sposób i w jakim zakresie zaprezentowane powyżej metody nauczania międzykulturowego mogą znaleźć zastosowanie w edukacji thumaczy w celu rozwijania poszczególnych komponentów kompetencji translatorskiej.

Przede wszystkim należy podkreślić, że metody międzykulturowe mogą najlepiej sprawdzać się w edukacji dorosłych ze względu na fakt, że obejmują one nie tylko rozwój wiedzy, ale także umiejętności i odpowiednich postaw, co wymaga od uczących się gotowości do: pracy niezależnie od nauczyciela, dokonywania refleksji nad sobą i własną tożsamością, a także zmiany perspektyw poznawczych. Zasadnym wydaje się więc stwierdzenie, że takie cele będą najskuteczniej realizuje się w pracy osobami dorosłymi, które charakteryzują się stosunkowo wysokim stopniem dojrzałości, a także zdolnością do wykonywania zadań opartych na dużej autonomii i wymagających dociekania znaczeń.

Przydatność metod zaczerpniętych z nauczania międzykulturowego w dydaktyce przekładu najłatwiej ocenić, analizując umiejętności, które pozwalają rozwijać w odniesieniu do elementów kompetencji translatorskiej, czego dokonano poniżej. Trzeba jednocześnie podkreślić, że wyniki tej oceny nie są wyczerpujące i wskazują jedynie, które kompetencje w najbardziej oczywisty sposób mogą być rozwijane z wykorzystaniem omówionych metod międzykulturowych.

Metody etnograficzne pomagają translatorom-uczniom zbierać informacje kulturowe, a także analizować je krytycznie, przez co mogą oni budować własne rozumienie pojęcia kultury oraz konkretnych kultur. W efekcie, mogą rozwijać kompetencję kulturową, ale także ćwiczyć dokładnie to, czego wymagać będzie od nich 
praca thumacza, czyli: analizować dokumenty lub kontekst wydarzeń, w tym ukrytych zjawisk kulturowych, które są ich istotą. W ten sposób studenci zyskują również szansę na rozwijanie swoich kompetencji w zakresie wyszukiwania informacji.

Szczególnie przydatną metodą etnograficzną wydają się być zadania wymagające interpretacji tekstów, włącznie z zastosowaniem analizy semiotycznej, co daje szansę na rozwijanie kompetencji tekstowej, niezbędnej do wykonywania tłumaczeń pisemnych. Dodatkowym atutem tej metody jest nauka hermeneutyki na podstawie niewerbalnych środków komunikacji, które często towarzyszą dokumentom tekstowym, takich jak ilustracje, jak również elementów pośrednio związanych z tekstem, np. analizy potencjalnej grupy odbiorców.

Co więcej, jeśli metody etnograficzne obejmują pobyt w obcym kraju lub kulturowo obcym otoczeniu, daje to studentom szansę na wykorzystanie posiadanych umiejętności mediacyjno-komunikacyjnych w czasie rzeczywistym, co z kolei może być dobrym przygotowaniem do wykonywania tłumaczeń ustnych. Umiejętności rozwijane na skutek takiej interakcji mogą pomóc uczącym się zwiększyć ich wiedzę o języku docelowym (kompetencja językowa), a także wzorcach komunikacyjnych, bez znajomości których skuteczne tłumaczenie nie jest możliwe (kompetencja tekstowa).

W ujęciu ogólnym, wynikiem nauki z wykorzystaniem metod etnograficznych zdaje się być rozwijanie zdolność postrzegania tekstu źródłowego i docelowego w sposób obiektywny, dzięki czemu - poprzez lepsze zrozumienie potencjalnych problemów kulturowych - łatwiej podjąć się mediacji między autorem tekstu źródłowego i odbiorcą tekstu docelowego (kompetencja transferu).

Metody empiryczne pomagają studentom mediować w czasie rzeczywistym, co może okazać się szczególnie przydatne dla przyszłych thumaczy ustnych, którzy muszą posiadać umiejętność skutecznego przesyłania informacji między członkami różnych grup językowo-kulturowych. W toku tej pracy rozwijają zarówno kompetencję językową, jak i kompetencję transferu.

Ponieważ metody empiryczne kładą nacisk na bezpośrednie uczestnictwo uczniów w doświadczeniu międzykulturowym, poddanym późniejszej analizie i refleksji, które $\mathrm{z}$ kolei prowadzą do eksperymentowania ze zdobytą $\mathrm{w}$ ten sposób wiedzą - na przykład poprzez wykorzystanie cyklu Kolba (zob. Kolb 1984) - są one narzędziem, dzięki któremu rozwijana jest kompetencja poszukiwania informacji. Co więcej, tego typu działania umożliwią tłumaczom systematyczny rozwój przez całe życie, zgodnie z paradygmatem promowanym przez Radę Europy (2007). W efekcie, translator-uczeń może na bieżąco aktualizować swoją wiedzę na temat zmian zachodzących w systemach językowo-kulturowych.

Inną korzyścią płynącą z wykorzystania metod empirycznych jest umożliwienie uczącym się uczestnictwa $\mathrm{w}$ indywidualnych oraz grupowych zadaniach typu projektowego, dzięki czemu mają oni szansę doskonalić swoją wiedzę w zakresie konkretnych obszarów tematycznych (kompetencja dziedzinowa), a także nauczyć się, jak współpracować z innymi. Ten ostatni tryb pracy może również obejmować telekolaborację (kompetencja techniczna), czyli wykorzystanie narzędzi internetowych, 
które są coraz częściej stosowane przez współczesnych tłumaczy (zob. M. Mrochen 2014/ C. Zhang i H. Cai 2015).

Metody dialogiczne wydają się w sposób najbardziej bezpośredni łączyć się z pracą thumacza, jako że pośredniczą w kształceniu studentów w zakresie konstrukcji i dekonstrukcji tekstu. Dzięki tym zadaniom, poprzez analizę hermeneutyczną, uczący się uświadamiają sobie, jak konstruowane są poszczególne typy tekstów, uwzględniając przy tym krąg kulturowy, z którego teksty te się wywodzą. Tego rodzaju wiedza może przyczynić się do rozwoju kompetencji tekstowej uczniów, a na dłuższą metę także kompetencji transferu. W końcu, skuteczny transfer informacji z tekstu źródłowego do docelowego zależy od stopnia, w jakim tłumacz świadomy jest różnic $\mathrm{w}$ kodowaniu i dekodowaniu informacji przez przedstawicieli odmiennych kultur.

Metody porównawcze mogą sprzyjać rozwojowi kompetencji kulturowej, ale także kompetencji w zakresie wyszukiwania informacji, gdyż wymagają, by studenci zbierali, porównywali i interpretowali kulturowo zakodowane treści, a także analizowali znaczenia $w$ nich zawarte. Bardziej zaawansowane metody porównawcze pomagają translatorom-uczniom wypracować względnie obiektywny stosunek do odmienności, dzięki lepszemu zrozumieniu wzorców myślowych i wartości, które motywują konkretne zachowania kulturowe. Metody te pozwalają poznać w praktyce koncepcję languaculture (zob. M. Agar 1994).

Ponadto metody porównawcze motywują translatora-ucznia, by badać kwestie kulturowe samodzielnie i budować obraz kultury niezależnie od nauczyciela. W toku takiej pracy wykorzystują oni posiadaną już wiedzę i korzystają z dostępnych im zasobów, co pozwala im rozwijać kompetencję w zakresie wyszukiwania informacji, a także wyrobić nawyki przydatne w kształceniu ustawicznym (umiejętność uczenia się przez całe życie). Wartoś

cią dodaną w tym wypadku jest konieczność rozwiązywania przez uczących się problemów na własną rękę, co często stanowi nieodłączny element pracy tłumacza.

Tabelaryczne podsumowanie przydatności metod nauczania międzykulturowego w dydaktyce przekładu znajduje się poniżej:

\begin{tabular}{|l|l|}
\hline Metody międzykulturowe & \multicolumn{1}{|c|}{ Rozwijanie kompetencje } \\
\hline & kompetencja kulturowa \\
& kompetencja w zakresie wyszukiwania \\
Metody etnograficzne & informacji \\
& kompetencja tekstowa \\
& kompetencja lingwistyczna \\
& kompetencja transferu \\
\hline
\end{tabular}




\begin{tabular}{|c|l|}
\hline & kompetencja lingwistyczna \\
kompetencja transferu \\
Metody empiryczne & kompetencja w zakresie wyszukiwania \\
informacji \\
kompetencja techniczna \\
kompetencja dziedzinowa \\
umiejętność uczenia się przez całe życie \\
\hline Metody dialogiczne & $\begin{array}{l}\text { kompetencja tekstowa } \\
\text { kompetencja transferu }\end{array}$ \\
\hline Metody porównawcze & $\begin{array}{l}\text { kompetencja kulturowa } \\
\text { kompetencja w zakresie wyszukiwania } \\
\text { informacji } \\
\text { umiejętność uczenia się przez całe życie }\end{array}$ \\
\hline
\end{tabular}

Tabela 1. Przydatność metod nauczania międzykulturowego $w$ dydaktyce przekładu (propozycja autorska).

\section{Wnioski}

W świetle przeprowadzonej powyżej analizy można stwierdzić, że podejście międzykulturowe do nauki języka wydaje się mieć zastosowanie również w dydaktyce translacji na poziomie uniwersyteckim. Wniosek ten znajduje potwierdzenie w fakcie, iż cztery przeanalizowane metody nauczania międzykulturowego, tj. (i) metody etnograficzne, (ii) metody empiryczne, (iii) metody dialogiczne oraz (iv) metody porównawcze, wydają się pozwalać - przynajmniej potencjalnie - na rozwój głównych kompetencji składowych uwzględnianych w proponowanych w literaturze fachowej modelach kompetencji translatorskiej.

Metody te wydają się wspierać przede wszystkim rozwój kompetencji w zakresie wyszukiwania informacji, ponieważ autonomizują translatora-ucznia, zachęcając go do niezależnego badania języka i kultury, a także refleksji nad zaobserwowanymi zjawiskami. Ułatwiają również rozwój kompetencji tekstowej, przy czym studenci odkrywają kulturowe zasady konstrukcji tekstu, co pozwala im z kolei doskonalić umiejętność przenoszenia znaczeń z jednego typu tekstu do innego. W ten sposób translator-uczeń przygotowuje się do umiejętnego i skutecznego negocjowania znaczeń w przekładzie ustnym lub pisemnym.

Ze względu na fakt, że międzykulturowe podejście do nauki języków obcych, z którego zaczerpnięto omawiane metody nauczania, postrzega język i kulturę jako nierozłączne elementy, dodatkowo rozwija ono kompetencję językową, czyli znajomość reguł języka ojczystego i docelowego, oraz kulturową, dzięki czemu uczący się nabywają wiedzy i świadomości kulturowej. Oba te elementy nierozerwalnie łączą się z przekładem, którego bez nich nie będzie w stanie poprawnie wykonać tłumacz.

W wyniku przeprowadzonej analizy zauważyć można, że kompetencja techniczna okazuje się możliwa do rozwijania tylko z wykorzystaniem międzykulturowych metod empirycznych, a ponieważ współcześnie kompetencja ta znacząco zwiększyła swoje znaczenie w pracy tłumacza, teoretycznie może to niepokoić. Nie jest to jednak obawa uzasadniona, ponieważ po pierwsze, przeanalizowane w niniejszym arty- 
kule przykłady zastosowań omawianych metod międzykulturowych nie kładły szczególnego nacisku na wykorzystanie nowoczesnych technologii. Po drugie, praktycznie wszystkie metody międzykulturowe mogą być stosowane z wykorzystaniem całej gamy zadań opartych na technologii informacyjno-komunikacyjnych, a zagadnienie to szeroko omawia literatura fachowa, włącznie z przykładami praktycznych rozwiązań (zob. M. Marczak 2013/ M. Marczak, J. Krajka 2016). Tak więc, metody wspierać mogą w znacznie większej mierze rozwój kompetencji technicznej, włącznie $\mathrm{z}$ formami w trybie telekolaboracji.

Kompetencją translatorską, która wydaje się być najsłabiej wspomagana przez metody nauczania międzykulturowego, jest kompetencja dziedzinowa, która dotyczy znajomości konkretnej dyscypliny omawianej w tłumaczonym tekście. Nie oznacza to jednak, że jest to wniosek bezwzględnie prawdziwy, gdyż stopień, w jakim ta kompetencja jest rozwijana, zależy po prostu od aspektów kultury, jakie uczniowie badają z wykorzystaniem metod międzykulturowych lub od tematyki tekstów, z którymi pracują. Dobierając odpowiednio teksty wyjściowe i komponując właściwie zadania międzykulturowe, można zatem dość łatwo położyć nacisk właśnie na rozwój kompetencji dziedzinowej.

Nie wszystkie kompetencje składowe czy też konkretne umiejętności opisane w modelach kompetencji translatorskiej da się rozwijać z wykorzystaniem metod nauczania międzykulturowego. Należy jednak pamiętać, że metody te nie mogą być postrzegane jako panaceum na wszelkiego rodzaju wyzwania, jakie niesie ze sobą pedagogika przekładu. Stanowią one raczej uzupełnienie gamy rozwiązań, którymi dysponują dydaktycy i mogą w ciekawy oraz potencjalnie efektywny sposób przyczynić się do zwiększenia osiągnięć translatora-ucznia w toku studiów uniwersyteckich.

Reasumując, wdrażanie metod nauczania międzykulturowego do praktyki dydaktycznej nauczycieli przekładu na poziomie studiów uniwersyteckich wydaje się w pełni uzasadnione, ponieważ mogą one nie tylko potencjalnie rozwijać wybrane kompetencje translatora-ucznia, lecz również przygotować go do funkcjonowania w wielojęzycznym/ wielokulturowym społeczeństwie i zglobalizowanym, dynamicznie zmieniającym się świecie, zarówno w wymiarze zawodowym, jak i osobistym. Przedstawiony powyżej potencjał metod miedzykulturowych jest $\mathrm{w}$ rzeczywistości znacznie większy niż zaprezentowano, gdyż metody te sa niezwykle elastyczne w zastosowaniu, a co najważniejsze, obejmują jeszcze inne formy zadań niż tylko te, które ze względu na ograniczenia pojemnościowe wybrano do analizy na potrzeby niniejszego artykułu. Mając to na uwadze, trzeba podkreślić, że żadna z metod międzykulturowych nie powinna być postrzegana jako dominująca, a zauważalny brak równowagi w liczbie kompetencji translatorskich, których rozwijanie wspierają omawiane metody, wynika jedynie z natury przykładowych zadań, jakie tu omówiono.

Jednocześnie, pożądanym działaniem na przyszłość wydaje się przeprowadzenie empirycznej weryfikacji wniosków płynących z niniejszej analizy tak, by sprawdzić, na ile wykorzystanie metod nauczania międzykulturowego rzeczywiście skutkuje rozwojem poszczególnych komponentów kompetencji translatorskiej. Jest to zada- 
nie o tyle trudne, że rozwój jakichkolwiek kompetencji rozciągnięty jest w czasie i czasami trudno bezpośrednio go zmierzyć. Istnieją jednak techniki, które mogą okazać się pomocne w tym względzie. Ważne, by pomagały one łączyć ocenianie kompetencji translatora-ucznia na podstawie wyników wykonywanych przez niego zadań z bieżącą oceną procesu uczenia się - również na podstawie refleksji samego ucznia. Jest to możliwe w oparciu o prowadzoną przez niego na bieżąco dokumentację podejmowanych działań, np. w postaci zapisów w dzienniku zdarzeń czy pamiętniku lub na podstawie portfolio wykonanych prac, takich jak: tłumaczenia, mapy myśli, schematy, plakaty oraz pisemne analizy incydentów kulturowych. Instrumenty tego typu mogą okazać się niezbędne, zważywszy na fakt, że - jak wykazano powyżej - rozwijanie poszczególnych kompetencji łączy się nie tylko z nabywaniem mierzalnej wiedzy deklaratywnej (element kognitywny) i możliwych do zaobserwowania konkretnych umiejętności (element behawioralny), lecz również z kształtowaniem odpowiednich postaw (element afektywny), które często zmierzyć można jedynie pośrednio.

Jednak nawet zanim badania empiryczne pozwolą dokładniej ocenić wpływ metod międzykulturowych na rozwój kompetencji translatora-ucznia, warto próbować świadomie wplatać je w codzienną pracę dydaktyczną, korzystając $\mathrm{z}$ ich ogromnego potencjału i urozmaicając przy tym treść i formę przeprowadzanych zajęć.

\section{Bibliografia}

Agar, M. (1994), Language shock: Understanding e culture of conversation. New York.

Barro, A./ M. Byram/ H. Grimms/ C. Morgan. C. Roberts (1993), Cultural Studies for Advanced Language Learners, (w:) D. Graddol/ L. Thomson/ M. Byram (red.), Language and Culture. Clevedon, 193-209.

Barro, A./ S. Jordan/ C. Roberts (1998), Cultural practice in everyday life: the language learner as ethnographer, (w:) M. Byram/ M. Fleming (red.), Language Learning in Intercultural Perspective, Cambridge, 76-97.

Bolt, R. (2001), The Foreign Language Classroom, Culture and British Studies Reflections and Suggestions, (w:) M. Houten/ A. Pulverness (red.), New Directions New Opportunities. British Studies Conference Proceedings. Puławy Poland 9-12 March, 2000. Kraków, 95-113.

Byram, M. (1989), Cultural Studies in Foreign Language Education. Clevedon, Philadelphia.

Byram, M./ C. Morgan/ Colleagues (1994), Teaching-and-Learning Language-andCulture. Clevedon.

Byram, M. (1997), Teaching and Assessing Intercultural Communicative Competence. Clevedon.

Byram, M. (2008), From Foreign Language Education to Education for Intercultural Citizenship. Essays and Reflection. Clevedon, Philadelphia.

Campbell, S.J. (2010), Towards a Model of Translation Competence, (w:) Meta: Translators' Journal 36, 2-3, 329-43 (http://www.erudit.org/revue/ meta/1991/v36/n2-3/002190ar.pdf; pobrano 08.08.2016). 
Cevasco, M.E. (2000), British Studies at the University of Sao Paulo, (w:) A. Mountford/ N. Wadham-Smith (red.), British Studies: Intercultural Perspectives. Harlow, 14-18.

Collie, J. (2000), Teaching British Cultural Studies: Reflections on some Methodological Issues, (w:) A. Mountford/ N. Wadham-Smith (red.), British Studies: Intercultural Perspectives. Harlow, 141-150.

Cooper, A. (1998), Mind the gap! An ethnographic approach to cross-cultural workplace communication research, (w:) M. Byram/ M. Fleming (red.), Language Learning in Intercultural Perspective, Cambridge, 119-142.

Edgington, B. (2000), A Comparative Approach to Teaching British Studies: Problems and Perspectives, (w:) A. Mountford/ N. Wadham-Smith (red.), British Studies: Intercultural Perspectives. Harlow, 134-137.

EMT expert group (2009), Competences for professional translators, experts in multilingual and multimedia communication. Brussels.

Fenner, A. (2000), Cultural awareness, (w:) A. Fenner/ D. Newby (red.), Approaches to Materials Design in European Textbooks: Implementing Principles of Authenticity, Learner Autonomy, Cultural Awareness. Graz, 78-85.

Grucza, F. (1981), Zagadnienia translatoryki, (w:) F. Grucza (red.), Glottodydaktyka a translatoryka. Warszawa, 9-27.

Grucza, F. (1985), Lingwistyka, lingwistyka stosowana, glottodydaktyka, translato$r y k a$, (w:) F. Grucza (red.), Lingwistyka, glottodydaktyka, translatoryka. Warszawa, 19-44.

Grucza, S. (2004), Dydaktyka translacji. Terminologiczna preparacja dydaktycznych tekstów specjalistycznych, (w:) J. Lewandowski (red.), Leksykografia terminologiczna - teoria i praktyka. Warszawa, 243-267.

Huber-Kriegler, M./ I. Lázár/ J. Strange (2003), Mirrors and Windows. Strasbourg.

Kastberg, P. (2007), Cultural Issues Facing the Technical Translator, (w:) Journal of Specialised Translation 8, (www.jostrans.org/issue08/art_kastberg.php; pobrano 06.08.2016).

Kastendiek, H. (2000), Proposals for a Comparative Landeskunde Approach, (w:) A. Mountford/ N. Wadham-Smith (red.), British Studies: Intercultural Perspectives. Harlow, 69-81.

Kohonen, V./ R. Jaantinen/ P. Kaikkonen/ J. Lehtovaara (2001), Experiential Learning in Foreign Language Education. Harlow, England.

Kolb, D. (1984), Experiential learning. Englewood Cliffs, N.J.

Kołodziejczyk, D./ J. Lynn/ M. Żylińska (2000), Culture and Nationhood: First Stages in the Development of Comparative Cultural Studies, (w:) A. Mountford/ N. Wadham-Smith (red.), British Studies: Intercultural Perspectives. Harlow, $15-21$.

Kramsch, C. (1993), Context and Culture in Language Teaching. Oxford: Oxford University Press.

Marczak, M. (2013), Communication and Information Technology in (Intercultural) Language Teaching. Newcastle upon Tyne.

Marczak, M./ J. Krajka (2016). Assessing Intercultural Communicative Competence in Learning Management Systems, (w:) M. Rahman (red.), Integrating Technology and Culture: Strategies and Innovations in ELT. Jaipur, India. 
Montalt Ressurrecció, V., Piorno, P.E., Izquierdo, I.G. (2008). The Acquisition of Translation Competence, (w:) Translation Journal, 12 (4), http://translationjournal.net/journal/46competence.htm; pobrano 06.08.2016).

Mrochen, I. (2014), Translating in the Cloud: New Digital Skills and the Open Source Movement, (w:) E. Smyrnova-Trybulska (red.), E-learning and Intercultural Competences Development in Different Countries. Katowice/ Cieszyn, 279-296.

Müller-Hartmann, A. (2000). The Role of Tasks in Promoting Intercultural Learning in Electronic Learning Networks, (w:) Language Learning and Technology, 4 (2), 129-147.

PACTE group (2003), Building a Translation Competence Model, (w:) F. Alves (red.), Triangulating Translation: Perspectives in Process Oriented Research. Amsterdam/ Philadelphia, 43-66.

Płużyczka, M. (2009), Dydaktyka translacji - rozważania terminologiczne, (w:) Przegląd Glottodydaktyczny, 26, 195-200.

Pym, A. (2003), Redefining Translation Competence in an Electronic Age. In Defence of a Minimalist Approach. (w:) Meta: Translators' Journal, 48 (4), 481-497 (http://www.erudit.org/revue/meta/2003/v48/n4/008533ar.pdf; pobrano: 06.08.2016).

Rada Europy (2007), Key Competences for Lifelong Learning. European Reference Framework. Luxembourg.

Raw, L. (1998) Intercultural competence: does it exist?, (w:) R. Cherrington/ L. Davcheva (red.), Teaching Towards Intercultural Competence. Conference Proceedings. Sofia: Tilia, 34-44.

Schaeffner, C./ B. Adab (red.) (2000), Developing Translation Competence. Amsterdam/ Philadelphia.

Sercu, L. (1998), In-service teacher training and the acquisition of the intercultural competence, (w:) M. Byram/ M. Fleming (red.), Language Learning In Intercultural Perspective. Approaches through drama and ethnography. Cambridge, 255289.

Sim, R. (2000), A training strategy for translation studies, (w:) C. Schaeffner/ B. Adab (red.), Developing Translation Competence. Amsterdam/ Philadelphia, 171-184.

Tomalin, B./ S. Stempleski (1993), Cultural Awareness. Oxford.

Winkler, G. (1992), An engineered approach at Flensburg Polytechnic, (w:) C. Dollerup/ A. Loddegaard (red.), Teaching Translation and Interpreting: Training, Talent and Experience. Amsterdam/ Philadelphia, 99-104.

Zhang, C./ H. Cai (2015), On Techonological Turn of Translation Studies: Evidences and Influences. (w:) Journal of Language Teaching and Research, 6 (2), 429 434.

Żmudzki, J. (2009), Problemy, zadania i wyzwania translatoryki. (w:) Lingwistyka Stosowana/ Applied Linguistics/ Angewandte Linguistik, 1, 41-60. 